Published in final edited form as:

Int J Pharm. 2018 June 15; 544(2): 350-357. doi:10.1016/j.ijpharm.2017.11.064.

\title{
Advances in bioresponsive closed-loop drug delivery systems
}

\author{
Jicheng Yua,b, Yuqi Zhanga,b, Junjie Yana,b,c, Anna R. Kahkoska ${ }^{d}$, and Zhen Gua,b,d, \\ aJoint Department of Biomedical Engineering, University of North Carolina at Chapel Hill and \\ North Carolina State University, Raleigh, NC 27695, USA \\ ${ }^{\mathrm{b}}$ Center for Nanotechnology in Drug Delivery and Division of Molecular Pharmaceutics, UNC \\ Eshelman School of Pharmacy, University of North Carolina at Chapel Hill, Chapel Hill, NC \\ 27599, USA
}

"Key Laboratory of Nuclear Medicine, Ministry of Health, Jiangsu Key Laboratory of Molecular Nuclear Medicine, Jiangsu Institute of Nuclear Medicine, Wuxi 214063, PR China

dDepartment of Medicine, University of North Carolina at Chapel Hill, Chapel Hill, NC 27599, USA

\begin{abstract}
Controlled drug delivery systems are able to improve efficacy and safety of therapeutics by optimizing the duration and kinetics of release. Among them, closed-loop delivery strategies, also known as self-regulated administration, have proven to be a practical tool for homeostatic regulation, by tuning drug release as a function of biosignals relevant to physiological and pathological processes. A typical example is glucose-responsive insulin delivery system, which can mimic the pancreatic beta cells to release insulin with a proper dose at a proper time point by responding to plasma glucose levels. Similar self-regulated systems are also important in the treatment of other diseases including thrombosis and bacterial infection. In this review, we survey the recent advances in bioresponsive closed-loop drug delivery systems, including glucoseresponsive, enzyme-activated, and other biosignal-mediated delivery systems. We also discuss the future opportunities and challenges in this field.
\end{abstract}

\section{Keywords}

Closed-loop; Drug delivery; Bioresponsive; Glucose-responsive; Enzyme-responsive

\section{Introduction}

In living organisms, homeostatic regulation plays a critical role in enabling precisely tuned functionality in dynamic and variable environments, such as hormones secretion, ionic balance, and immune response (Fink, 1979; Lenardo et al., 1999). Homeostatic dysregulation is central to the pathogenesis of diseases such as diabetes and other autoimmune diseases (Gambineri et al., 2003; Mo et al., 2014). During the last few decades, closed-loop drug delivery systems have been explored as a promising alternative to

*Corresponding author at: Joint Department of Biomedical Engineering, University of North Carolina at Chapel Hill and North Carolina State University, Raleigh, NC 27695, USA. zgu@email.unc.edu, zgu3@ ncsu.edu (Z. Gu). 
conventional drug delivery for homeostatic regulation (Gordijo et al., 2011; Lee et al., 2013; Ravaine et al., 2008). Unlike open-loop systems including immediate-release and sustainedrelease formulations, these smart drug delivery systems release therapeutics with tunable amount at the right time, thus controlling drug release as a function of biosignals relevant to pathological processes (Byrne et al., 2002; Caldorera-Moore et al., 2011) (Fig. 1). One typical example is the closed-loop insulin delivery system, which releases insulin only in conditions where it is appropriate, such as rising blood glucose levels (Veiseh et al., 2015; Yu et al., 2016a; Zhang et al., 2015).

The closed-loop drug delivery systems usually consist of a monitoring component that senses the surrounding conditions and an actuator component with the capability to trigger drug release (Lu et al., 2016; Mura et al., 2013; Stuart et al., 2010). The pairing of the monitor/actuator architecture allows the drug release activated at or above a certain biosignal concentration or threshold but inhibited when the biosignal level is in normal ranges (Bawa et al., 2009; Lu et al., 2014; Park, 2014). Closed-loop medical devices consisting of a continuous sensor and an external drug infusion pump is one typical type of self-regulated drug delivery systems. Besides, a chemical approach based on bioresponsive materials has also received a great attention during the last few decades. In this review, we will summarize the recent advances in the development of closed-loop drug delivery systems based on bioresponsive materials, including glucose-responsive, enzyme-activated, and other biosignal-controlled systems. The challenges and future opportunities will also be discussed.

\section{Glucose-responsive closed-loop insulin delivery systems}

Properly dosed and timed insulin is essential to regulate blood glucose level for individuals with type 1 diabetes and advanced type 2 diabetes (Owens et al., 2001; Veiseh et al., 2015). Traditional open-loop insulin delivery requires frequent blood sugar monitoring and multiple subcutaneous injections with or after meals (Atkinson and Eisenbarth, 2001; Heinemann, 2011; Ismail-Beigi, 2012). However, there are deep challenges associated with the open insulin delivery method that prevents patients from obtaining tight glucose control, increasing the risk for diabetic complications including blindness, limb amputation, and kidney failure (Atkinson and Eisenbarth, 2001; Bratlie et al., 2012). A closed-loop system mimicking the pancreatic beta cells to "secrete" insulin in response to blood glucose levels has been considered as a desirable strategy for the treatment of type 1 and advanced type 2 diabetes (Mo et al., 2014; Veiseh et al., 2015). Such systems are typically comprised of a glucose-sensing module and a relevant actuator. Although closed-loop electronic/mechanical devices comprising of a continuous glucose monitoring and an insulin infusion pump have been already developed, some challenges still need to be addressed such as achieving accurate signal feedback and avoiding biofouling. An alternative approach to achieve closedloop insulin delivery is based on glucose-responsive chemical materials. We will introduce recent glucose-responsive closed-loop insulin delivery systems based on glucose oxidase (GOx), glucose binding proteins (GBPs), and phenylboronic acid (PBA), respectively. 


\subsection{Glucose oxidase (GOx)-based systems}

2.1.1. $\mathrm{pH}-\mathrm{pH}$-sensitive polymeric matrix containing glucose oxidase (GOx) was developed as the first glucose-responsive material in the 1980s (Fischel-Ghodsian et al., 1988). As a glucose sensing element, GOx reacts with glucose in the presence of oxygen and converts it into gluconic acid, leading to a decrease in pH (Bankar et al., 2009; Chen et al., 2013). The $\mathrm{pH}$-sensitive polymeric matrix subsequently responds to the $\mathrm{pH}$ change, swelling to facilitate insulin release. Peppas and coworkers also applied $\mathrm{pH}$-sensitive hydrogels to synthesize glucose-responsive insulin delivery, where the hydrogels swells or shrinks in response to changing $\mathrm{pH}$ to adjust insulin release in a glucose-mediated manner (Hassan et al., 1997; Podual et al., 2000). Based on this concept, several groups have developed glucose-responsive closed-loop insulin delivery systems that incorporate $\mathrm{pH}$-sensitive materials over the last decades (Di et al., 2015; Gordijo et al., 2010; Gu et al., 2013b; Kang and Bae, 2003; Zhao et al., 2011).

Langer, Anderson, and coworkers designed an injectable polymeric network consisting of GOx-loaded acid-degradable nanoparticles to achieve self-regulated insulin delivery (Gu et al., 2013a, b). The pH-sensitive material, acetal-modified dextran, was utilized to encapsulate insulin and enzymes by a double emulsion method. By coating the dextran nanoparticles with oppositely charged polymers respectively, they formed injectable gel-like nano-network. After injection into diabetic mice, this nano-network could sense the blood glucose levels and undergo subsequent nanoparticle dissociation to release insulin in an ondemand manner and effectively control glycemia for up to ten days. Later, Tai et al. synthesized a glucose-responsive diblock polymer for closed-loop insulin delivery. This $\mathrm{pH}-$ sensitive amphiphilic polymer self-assembled into nanovesicles with a polymersomestructure (Tai et al., 2014). When integrated with a themoresponsive hydrogel, this system was able to regulate blood glucose levels in type 1 diabetic mice based on a similar response mechanism previously described.

2.1.2. Hypoxia-An alternative method to using the $\mathrm{pH}$ decrease as a trigger for drug release is to leverage the rapid oxygen consumption during the oxidation of glucose as the signal to activate insulin release (Yu et al., 2016b). Recently, Yu et al. developed a glucoseresponsive insulin delivery device based on hypoxia-sensitive nanovesicles (Fig. 2A) (Yu et al., 2015). 2-nitroimidazole (NI), a hypoxia-sensitive group that is commonly used in hypoxia imaging for cancer therapy, was conjugated to the side chains of hyaluronic acid (HA). The resulting amphiphilic polymers readily self-assembled into a nano-size vesicle to encapsulate insulin and GOx. In the presence of high glucose concentrations, oxygen consumption during the enzymatic oxidation resulted in hypoxia and hydrophobic NI groups were quickly reduced into hydrophilic 2-aminoimidazole, thereby resulting in the disassembly of the nanovesicles and subsequent insulin release. In order to achieve an easy, convenient and painless administration (Martanto et al., 2004; Prausnitz, 2004; Yu et al., 2017b), these hypoxia-sensitive nanovesicles were further integrated with a microneedles (MNs)-array patch for diabetes treatment (Fig. 2B). Compared to the acid-responsive materials, these patches could correct hyperglycemic blood glucose levels to a normal state within $30 \mathrm{~min}$ and maintain control for several hours after application in type 1 diabetic mice (Fig. 2C). Utilizing glucose-responsive nanovesicles, $\mathrm{Gu}$ and coworkers further 
introduced live beta cells to achieve an externally positioned cell-based insulin delivery which acted as both a glucose sensor and a signal amplifier (Ye et al., 2016).

2.1.3. $\mathrm{H}_{2} \mathrm{O}_{2}$-During the enzymatic oxidation of glucose, a further byproduct, $\mathrm{H}_{2} \mathrm{O}_{2}$, is quickly generated under a high glucose concentration. Thus, $\mathrm{H}_{2} \mathrm{O}_{2}$-sensitive materials can also be leveraged to achieve a glucose-responsive insulin delivery system. Block polymers consisting of phenylboronic ester (PBE)-modified polyserine and polyethylene glycol were synthesized to deliver insulin by $\mathrm{Gu}$ and coworkers (Hu et al., 2017). The resulting copolymers were amphiphilic and self-assembled into polymersome nanovesicles to encapsulate insulin and GOx. When exposed to high glucose conditions, the rapidlygenerated $\mathrm{H}_{2} \mathrm{O}_{2}$ readily reacted with the block polymer to degrade the pendant PBE, improving the water-solubility of the polymer and facilitating the gradual dissociation of nanovesicles to release insulin. They also loaded these $\mathrm{H}_{2} \mathrm{O}_{2}$-sensitive nanovesicles into a painless microneedle patch for in vivo study to show that blood glucose levels were maintained within the normal levels over the first $5 \mathrm{~h}$ after application in type 1 diabetic mice.

In another example, Yu et al. integrated both $\mathrm{H}_{2} \mathrm{O}_{2}$-sensitive and hypoxia-sensitive groups to obtain a dual-sensitive polymer (Yu et al., 2017a). The hypoxia-sensitive NI moiety was conjugated to the poly (ethylene glycol)(PEG)-polyserine backbone via a $\mathrm{H}_{2} \mathrm{O}_{2}$-sensitive thioether linker to achieve an amphiphilic copolymer. Following the oxygen consumption and generation of $\mathrm{H}_{2} \mathrm{O}_{2}$, NI and thioether moieties were converted into hydrophilic 2aminoimidazole and sulfone groups, respectively. The enhancement of water solubility contributed to the disassembly of polymeric vesicles and subsequent insulin release. Loaded on a micro-needle patch, the glucose-responsive vesicles were shown to regulate blood glucose levels in a diabetic mouse model. Furthermore, unlike the hypoxia-sensitive formulation, this dual-sensitive design successfully eliminated the toxic $\mathrm{H}_{2} \mathrm{O}_{2}$, which could minimize the skin inflammation and enhance biocompatibility of the device.

\subsection{Glucose binding proteins (GBPs)-based systems}

Over the last decade, many glucose-responsive insulin delivery strategies have been exploited based on the selective binding between GBPs and glucose (Liu et al., 1997; Veiseh et al., 2015; Yu et al., 2016a). A lectin from the jack bean, concanavalin A (Con A), is commonly used as the glucose sensing moiety (Parmpi and Kofinas, 2004). Con A has four binding sites for reversible affinity to D-glucose, D-mannose, and polysaccharides (Brownlee and Cerami, 1979; Sharon and Lis, 1972). In the 1970s, Brownlee and Cerami first applied Con A to design a glucose-responsive insulin delivery system, where a glycosylated insulin derivative was synthesized and bound to Con A (Brownlee and Cerami, 1979). In the presence of high glucose concentrations, the insulin derivative was released by competitive replacement of free glucose. Kim and coworkers also synthesized gluconic acid-modified insulin to complementarily bind to Con A for self-regulated insulin release (Makino et al., 1990; Seminoff et al., 1989). In addition, the reversible binding between Con A and polysaccharides like dextran and chitosan allows the fabrication of glucose-responsive hydrogel materials. For instance, Nie and coworkers developed glucose-triggered insulin 
hydrogels that could release insulin due to swelling and hydrolyzation in the presence of increasing glucose levels (Yin et al., 2012, 2014).

Recently, Gu and coworkers utilized native red blood cells as the drug carriers to achieve glucose-responsive insulin delivery (Fig. 3) (Wang et al., 2017). The glucosamine-modified insulin derivative (Glc-Insulin) can bind to the glucose transporter (GLUT), an abundant membrane protein on red blood cells (Mueckler, 1994). Since this affinity is reversible, GlcInsulin is quickly released from the red blood cells due to the competitive interaction of free glucose with GLUTs in hyperglycemic conditions. Using the chemically-induced type 1 mouse model, they demonstrated that one single intravenous injection of these "glucoseresponsive cells" was able to reduce the blood glucose levels for 3 days. Since red blood cells have a long life span of about 100 days, these insulin-loaded cells have a potential for in vivo long-term glucose-responsive insulin delivery (Muzykantov, 2010). The same authors also synthesized RBC membranes cloaked nanoplatforms for closed-loop insulin delivery based on the same mechanism (Wang et al., 2017).

\subsection{Phenylboronic acid (PBA)-based systems}

PBA is a synthetic molecule that can interact with diols to form a 5-or 6-membered ring cyclic boronate ester (Kataoka et al., 1995). Ever since the reversible binding between PBA and sugar was discovered by Lorand and Edwards in 1959, PBA-based devices have been widely exploited for diabetes diagnosis, glucose sensors, and closed-loop insulin delivery (Brooks and Sumerlin, 2015; Bull et al., 2012; Lorand and EDWARDS, 1959).

Kataoka, Okana and coworkers described a glucose-responsive insulin device composed of glycosylated insulin-loaded PBA gel beads via the formulation of boronate ester (Shiino et al., 1994), where the PBA gel beads released insulin in response to environmental glucose concentrations. Lin and coworkers applied PBA-modified mesoporous silica nanoparticles (PBA-MSNs) as the carriers for a glucose-responsive drug delivery system in which the gluconic acid-modified insulin could link to the PBA groups on the surface of PBA-MSNs and also act as the gatekeepers to entrap another drug, cyclic adenosine monophosphate (cAMP), in the pores of MSNs (Zhao et al., 2009). The insulin and cAMP release rates were controlled by blood glucose levels. In addition to the hypoglycemic effect induced by insulin, the released cAMP was able to further stimulate the insulin secretion from pancreas $\beta$ cells, achieving self-regulated drug delivery.

Kim and coworkers further leveraged the charge transition in PBA molecules associated with glucose binding to design glucose-responsive polymersomes (Kim et al., 2012). They synthesized an amphiphilic block copolymer composed of a monosccharide-sensitive poly(styr-eneboroxole) (PBOx) segment and a hydrophilic PEG block, which self-assembled into polymeric vesicles to encapsulate insulin. In hyperglycemic conditions, the PBOx block could interact with glucose to transform from an undissociated, neutrally charged form to a dissociated anionic form, leading to the dissociation of the polymersomes and subsequent insulin release. Matsumoto et al. investigated a glucose-responsive hydrogel based on a PBA-conjugated thermo-sensitive polymer (Matsumoto et al., 2012). The dehydrated surface served as a "skin layer" to control the insulin diffusion from the gel, while the glucosemediated shift from the uncharged PBA to the charged form altered the volume of the gel, 
resulting in a rapid insulin release in hyperglycemic conditions. The glucose-induced phase transition allowed this insulin-loaded gel act as a closed-loop device to realize human glucose homeostasis.

\section{Enzyme-responsive closed-loop delivery systems}

Enzymes play a central role in many biological and metabolic processes and the dysregulation of enzyme expression is associated to the progression of many diseases (Hu et al., 2014; Lee et al., 2004; Turk, 2006). Therefore, specific enzymes act as important signals for diagnosis as well as promising triggers for specific drug delivery (De La Rica et al., 2012). In enzyme-responsive closed-loop delivery systems, the activity or the overexpression of enzymes are suppressed following the action of the released drug. Then, enzymetriggered drug release is turned off to avoid potential side effects.

\subsection{Thrombin}

For example, thrombin is responsible for converting soluble fibrinogen to insoluble fibrin and acts as the key enzyme in blood coagulation cascade (Mackman, 2008). Abnormal increases in blood thrombin levels can cause vascular occlusions and severe cardiovascular diseases (Engelmann and Massberg, 2013). Heparin is a common anticoagulant used in precise doses to counteract such coagulation activation (Collins et al., 1988). To more precisely dose heparin levels and prevent associated side effects, Maitz et al. designed a direct control loop system to deliver heparin in amounts tuned by the environmental thrombin levels (Maitz et al., 2013). In this system, heparin was covalently linked to multiarmed PEG through a thrombin-cleavable peptide to form a thrombin-responsive polymeric hydrogel (Fig. 4A). When thrombin levels increased, heparin was rapidly released due to the cleavage of the peptides, after which the free heparin is able to accelerate the formation of the complexation of thrombin and antithrombin, a natural thrombin inhibitor. This downregulation of the trigger (thrombin) caused by release of heparin creates a feedback loop, allowing for the sensitive control the thrombin activity and the associated regulation of anticoagulation activity. This closed-loop hydrogel was shown to effectively prevent the formation of blood clots over several hours during repeated incubation with fresh blood, while non-responsive heparin-loaded hydrogel could only quench blood coagulation in the first incubation with whole blood when heparin was released in full.

Utilizing the thrombin-cleavable peptide, Lin et al. also reported an electrostatic nanocomplex consisting of anionic heparin and cationic peptides for homeostatic regulation of the coagulation cascade (Lin et al., 2014). The thrombin-triggered cleavage of the peptides facilitated self-titrating anticoagulation activity that simultaneously decreased the risk of unwanted bleeding. Similarly, Bhat et al. applied the thrombin-responsive peptide as a gatekeeper to control the release of acenocoumarol, another anticoagulant drug, from mesoporous silica nanoparticles (MSNs) (Bhat et al., 2016). In order to achieve continuous, prolonged, convenient, and painless administration, Zhang et al. integrated a thrombinresponsive heparin-loaded hydrogel with a transcutaneous microneedle-array patch for autoanticoagulant regulation, where the heparin was conjugated to a hyaluronic acid (HA) hydrogel via the thrombin-cleavable peptide (Fig. 4B) (Zhang et al., 2016). Once inserted 
into skin, this transcutaneous patch could sense the thrombin levels in capillary blood circulation, and there was little drug leaked from the patch in normal blood environments. However, the system effectively responded to the elevated thrombin level by releasing a proper dose of heparin to avoid blood clots. In in vivo studies, the researchers demonstrated that this bioresponsive patch could effectively prevent undesirable coagulation. Furthermore, unlike the non-responsive heparin-loaded patch, the patch with feedback-controlled capability provided a long-term protection from acute pulmonary thromboembolism that lasted 6-hour post administration.

\subsection{Lipase}

Secreted lipases act as important persistence and virulence factors in the event of bacterial and fungal infections (Singh and Mukhopadhyay, 2012). Therefore, a lipase-activated drug delivery system has been explored to specifically inhibit bacterial and fungal growth. For example, Wang and coworkers described a lipase-sensitive polymeric triple layered nanogel for bacterial-activated drug delivery (Xiong et al., 2012). The model antimicrobial drug was entrapped in the polyphosphoester core and surrounded with hydrophobic poly $(\varepsilon$-caprolactone) (PCL) segments and hydrophilic PEG to prevent nonspecific antibiotic release (Fig. 5). When the nanogels were in the presence of lipase-secreting bacteria, the PCL layer was gradually degraded to release the antimicrobial drug to inactivate bacteria and subsequently reduce lipase secretion. This triple-layered nanogel exhibited significant efficiency to treat extracellular and intracellular bacterial infections without potential side effects. Another lipase-triggered formulation was reported by Loh and coworkers for potential treatment of fungal infection, where the lipase-sensitive polymer, polysorbate 80, was used to stabilize the phytantriol nanoparticles (Poletto et al., 2016). Lipase-mediated hydrolysis of polysorbate 80 to give polyethoxylated sorbitan and oleic acid resulted in a structural transition of the nano-particle and consecutively triggered specific drug release. Aside from lipases, specific enzymes associated with different bacterial strains have also been recently exploited as the triggers to realize on-demand delivery of antimicrobial agents for bacterial strain-selective inhibition (Li et al., 2016).

Lipase is also a key enzyme for hydrolysis and absorption of food in the digestive tract, and partial deactivation of lipase can inhibit excess fat digestion and balance calorie intake (de la Garza et al., 2011). Therefore, Shen and coworkers developed a smart lipase-responsive drug delivery system for negative feedback regulation of lipase activity (Chen et al., 2016). The lipase-degradable PCL was modified to the side chains of the fluorescent conjugated polymers, and the resulting amphiphilic copolymer was self-assembled into nanoparticles to encapsulate the lipase inhibitor drug, orlistat. Following oral administration, lipase released in the intestine catalyzed the degradation of the nanoparticles to release orlistat; the released orlistat irreversibly deactivated the lipase to reduce the intestinal absorption of dietary fats.

Meanwhile, the inactivation of lipase shut down the degradation of the nanoparticles to tune the orlistat release rate in a negative feedback manner. In this closed-loop strategy, the nanoparticles were shown to be efficient in prevention of weight gain in a diet-induced obesity mouse model with few side effects. 


\section{Others biosignals-controlled closed-loop systems}

\section{1. $\mathrm{CO}_{2}$}

Closed-loop drug delivery systems also hold great promise for the controlled release of antidotes in response to opioid overdose. Morphine, an opiate analgesic, is administered to relief both acute and chronic severe pain (Çoban et al., 2007). However, morphine overdoses decrease reduced respiratory effort and lower blood pressure, resulting in decreased blood $\mathrm{O}_{2}$ levels, increased $\mathrm{CO}_{2}$ concentration and acidosis-induced death (Le Le Guen et al., 2002). An on-demand delivery of antidote can effectively eliminate the risk of morphine overdose. Therefore, Heller and coworkers developed a morphine-triggered antidote delivery device consisting of an enzyme-coated erodible polymeric core loaded with drug and a cellulose dialysis tube with enzyme lipases inactivated by the covalent conjugation with morphine and complexing with an antibody to morphine (Roskos et al., 1995). Free morphine is able to displace the lipase-morphine complex from antibody and allow the rapid degradation of polymeric core to release drug. Satav et al. designed another self-regulated antidote delivery system by taking advantage of $\mathrm{CO}_{2}$ as a danger signal (Satav et al., 2010). The $\mathrm{CO}_{2}$-responsive hydrogel-based delivery vehicle was prepared from functional $\mathrm{N}, \mathrm{N}$ dimethylaminoethyl methacrylate (DMAEMA) monomer and tri-methylolpropane trimethacrylate (TMPTMA) crosslinker. In the presence of increased blood $\mathrm{CO}_{2}$ levels and the associated decrease in $\mathrm{pH}$, the protonation of the amine groups of DMAEMA causes the swelling of the $\mathrm{pH}$-sensitive hydrogel and accelerates drug release. This system's remarkable control of antidote release against the toxic marker concentration has great potential to prevent serious side effects of drug overdose.

\subsection{Urea}

Urea-responsive drug delivery has also been explored based on the enzymatic activity of urease, which hydrolyses urea into $\mathrm{NH}_{4} \mathrm{HCO}_{3}$ and $\mathrm{NH}_{4} \mathrm{OH}$ (Krajewska, 2009). As this enzymatic reaction causes an increase in $\mathrm{pH}$, Heller and Trescony developed a urearesponsive delivery device based on a pH-sensitive bioerodible polymer (Heller and Trescgny, 1979). A model drug, hydrocortisone, was mixed with a partially esterified copolymer of methylvinylether and maleic anhydride to fabricate into disks, which were coated with urease-immobilized hydrogel. In the presence of external urea, the $\mathrm{pH}$ increase was able to accelerate the polymer erosion and drug release. Similarly, Ishihara et al. designed a pH-sensitive membrane instead of the erodible polymer for urea-responsive closed-loop delivery (Ishihara et al., 1985a, b). The permeation of the drug through the 4carboxy acryla-nilide-methyl methacrylate membrane was modulated by change in $\mathrm{pH}$ caused by the urease-mediated urea conversion.

\subsection{Ions}

Based on the many kinds of cations and anions in body fluids such as blood, gastrointestinal fluid, sweat and tears, ion-responsive delivery systems can sense a variety of ions concentrations in body fluid and modulate the drug release rate for optimal drug therapy. For instance, $\mathrm{Na}^{+}$ion commonly exists in the wound exudates and Huang et al. described a $\mathrm{Na}^{+}-$ sensitive alginate gel loaded with nano-silver as a non-specific antimicrobial agent for wound dressing applications (Huang et al., 2015). Upon administration to the wound, the 
alginate gel swelled due to the ion-exchange of $\mathrm{Na}^{+}$, thereby opening the lock between $\mathrm{Ca}^{2+}$ and guluronic residues on alginate to result in subsequent release of nano-silver. Since the extent of alginate gel swelling was tuned by the volume of wound exudates, the release rate of nano-silver was effectively self-regulated during the wound healing process, achieving a closed-loop drug delivery strategy. Chu and coworkers also developed a $\mathrm{K}^{+}$-sensitive hydrogel consisting of crown ether 15-crown-5 as the ion-sensor and poly $(\mathrm{N}-$ isopropylacrylamide) as the actuator for self-regulated controlled release (Mi et al., 2010). In this system, $\mathrm{K}^{+}$bound to the crown ether 15 -crown- 5 based on a 2:1 "host-guest" complexation formulation to drive the shrinkage of the hydrogel, giving a pulse-release mode that was regulated by changing environmental $\mathrm{K}^{+}$concentration.

\section{Conclusions and future directions}

During the past several decades, many sensing mechanisms have emerged, which provide new control strategies for designing closed-loop drug delivery systems. For such systems, numerous bioresponsive materials are utilized to construct functional modules for the desired devices. Therapeutics is designed to be controlled released from drug carriers through the structural transformations such as shrinking, swelling, and dissociation or unique responsive cleavage route. Table 1 summarizes the typical closed-loop drug delivery systems recently reported in this review. These emerging smart devices have been proven to be capable to enhance therapy efficiency and reduce adverse effect in drug administration, demonstrating vast potential in fields including diabetes management, auto-anticoagulation regulation, and antibiotic therapy in both the research and the clinical sector. Despite the advancements, translation of a clinically effective and safe closed-loop delivery system remains challenged by several aspects. For example, in order to achieve the precise delivery, relevant parameters of materials and formulation should be carefully tailored. Meanwhile, it is important to set uniformity for the evaluation of the devices in clinical trials. Second, a thorough understanding of the role of biosignals in diseases is required to design an effective closed-loop system. It is critical to differentiate the target biosignal from its analogues to enhance specificity of delivery systems. Moreover, long-term prevention and treatment with closed-loop systems requires sufficient sustained biocompatibility. Thorough assessment of materials and effective elimination of toxic substance must be taken into consideration. Aside from these challenges, identifying and leveraging new monitor/actuator pairs is also important to design novel closed-loop drug delivery devices, especially those that may be used for prevalent metabolic diseases (Bakh et al., 2017).

\section{Acknowledgments}

This work was supported by the grants from the American Diabetes Association (ADA) (grant no. 1-15-ACE-21) and National Science Foundation (grant no. 1708620) to Z.G.)

\section{References}

Atkinson MA, Eisenbarth GS. Type 1 diabetes: new perspectives on disease pathogenesis and treatment. Lancet. 2001; 358:221-229. [PubMed: 11476858]

Bakh NA, Cortinas AB, Weiss MA, Langer RS, Anderson DG, Gu Z, Dutta S, Strano MS. Glucoseresponsive insulin by molecular and physical design. Nat Chem. 2017; 9:937-943. [PubMed: 28937662] 
Bankar SB, Bule MV, Singhal RS, Ananthanarayan L. Glucose oxidase-an overview. Biotechnol Adv. 2009; 27:489-501. [PubMed: 19374943]

Bawa P, Pillay V, Choonara YE, Du Toit LC. Stimuli-responsive polymers and their applications in drug delivery. Biomed Mater. 2009; 4:022001. [PubMed: 19261988]

Bhat R, Ribes À, Mas N, Aznar E, Sancenón F, Marcos MD, Murguía JR, Venkataraman A, MartínezMáñez R. Thrombin-responsive gated silica mesoporous nanoparticles as coagulation regulators. Langmuir. 2016; 32:1195-1200. [PubMed: 26794474]

Bratlie KM, York RL, Invernale MA, Langer R, Anderson DG. Mater. Diabetes Ther Adv Healthc Mater. 2012; 1:267-284.

Brooks WL, Sumerlin BS. Synthesis and applications of boronic acid-containing polymers: from materials to medicine. Chem Rev. 2015; 116:1375-1397. [PubMed: 26367140]

Brownlee M, Cerami A. A glucose-controlled insulin-delivery system: semisyn-thetic insulin bound to lectin. Science. 1979; 206:1190-1191. [PubMed: 505005]

Bull SD, Davidson MG, Van den Elsen JM, Fossey JS, Jenkins ATA, Jiang YB, Kubo Y, Marken F, Sakurai K, Zhao J. Exploiting the reversible covalent bonding of boronic acids: recognition, sensing, and assembly. Acc Chem Res. 2012; 46:312-326. [PubMed: 23148559]

Byrne ME, Park K, Peppas NA. Molecular imprinting within hydrogels. Adv Drug Deliv Rev. 2002; 54:149-161. [PubMed: 11755710]

Caldorera-Moore ME, Liechty WB, Peppas NA. responsive theranostic systems: integration of diagnostic imaging agents and responsive controlled release drug delivery carriers. Acc Chem Res. 2011; 44:1061-1070. [PubMed: 21932809]

Chen C, Xie Q, Yang D, Xiao H, Fu Y, Tan Y, Yao S. Recent advances in electrochemical glucose biosensors: a review. RSC Adv. 2013; 3:4473-4491.

Chen YL, Zhu S, Zhang L, Feng PJ, Yao XK, Qian CG, Zhang C, Jiang XQ, Shen QD. Smart conjugated polymer nanocarrier for healthy weight loss by negative feedback regulation of lipase activity. Nanoscale. 2016; 8:3368-3375. [PubMed: 26790821]

Çoban TA, Beydemir Ş, Gülçin İ, Ekinci D. Morphine inhibits erythrocyte carbonic anhydrase in vitro and in vivo. Biol Pharm Bull. 2007; 30:2257-2261. [PubMed: 18057708]

Collins R, Scrimgeour A, Yusuf S, Peto R. Reduction in fatal pulmonary embolism and venous thrombosis by perioperative administration of subcutaneous heparin. New Engl J Med. 1988; 318:1162-1173. [PubMed: 3283548]

de la Garza AL, Milagro FI, Boque N, Campión J, Martínez JA. Natural inhibitors of pancreatic lipase as new players in obesity treatment. Planta Med. 2011; 77:773-785. [PubMed: 21412692]

De La Rica R, Aili D, Stevens MM. Enzyme-responsive nanoparticles for drug release and diagnostics. Adv Drug Deliv Rev. 2012; 64:967-978. [PubMed: 22266127]

Di J, Yu J, Ye Y, Ranson D, Jindal A, Gu Z. Engineering synthetic insulin-secreting cells using hyaluronic acid microgels integrated with glucose-responsive nanoparticles. Cell Mol Bioeng. $2015 ; 8: 445-454$.

Engelmann B, Massberg S. Thrombosis as an intravascular effector of innate immunity. Nat Rev Immunol. 2013; 13:34-45. [PubMed: 23222502]

Fink G. Feedback actions of target hormones on hypothalamus and pituitary with special reference to gonadal steroids. Annu Rev Physiol. 1979; 41:571-585. [PubMed: 373603]

Fischel-Ghodsian F, Brown L, Mathiowitz E, Brandenburg D, Langer R. Enzymatically controlled drug delivery. Proc Natl Acad Sci. 1988; 85:2403-2406. [PubMed: 3281165]

Gambineri E, Torgerson TR, Ochs HD. Immune dysregulation, poly-endocrinopathy, enteropathy, and $\mathrm{X}$-linked inheritance (IPEX), a syndrome of systemic autoimmunity caused by mutations of FOXP3, a critical regulator of T-cell homeostasis. Curr Opin Rheumatol. 2003; 15:430-435. [PubMed: 12819471]

Gordijo CR, Koulajian K, Shuhendler AJ, Bonifacio LD, Huang HY, Chiang S, Ozin GA, Giacca A, Wu XY. Nanotechnology-enabled closed loop insulin delivery device: in vitro and in vivo evaluation of glucose-regulated insulin release for diabetes control. Adv Funct Mater. 2011; 21:73-82.

Gordijo CR, Shuhendler AJ, Wu XY. Glucose-Responsive bioinorganic nano-hybrid membrane for self-regulated insulin release. Adv Funct Mater. 2010; 20:1404-1412. 
Gu Z, Aimetti AA, Wang Q, Dang TT, Zhang Y, Veiseh O, Cheng H, Langer RS, Anderson DG. Injectable nano-network for glucose-mediated insulin delivery. ACS Nano. 2013a; 7:4194-4201. [PubMed: 23638642]

Gu Z, Dang TT, Ma M, Tang BC, Cheng H, Jiang S, Dong Y, Zhang Y, Anderson DG. Glucoseresponsive microgels integrated with enzyme nanocapsules for closed-loop insulin delivery. ACS Nano. 2013b; 7:6758-6766. [PubMed: 23834678]

Hassan CM, Doyle FJ, Peppas NA. Dynamic behavior of glucose-responsive poly (methacrylic acid-gethylene glycol) hydrogels. Macromolecules. 1997; 30:6166-6173.

Heinemann L. New ways of insulin delivery. Int J Clin Pract. 2011; 65:31-46. [PubMed: 21155942]

Heller J, Trescgny P. Controlled drug release by polymer dissolution II: enzyme-mediated delivery device. J Pharm Sci. 1979; 68:919-921. [PubMed: 37327]

$\mathrm{Hu}$ Q, Katti PS, Gu Z. Enzyme-responsive nanomaterials for controlled drug delivery. Nanoscale. 2014; 6:12273-12286. [PubMed: 25251024]

Hu X, Yu J, Qian C, Lu Y, Kahkoska AR, Xie Z, Jing X, Buse JB, Gu Z. H2O2-responsive vesicles integrated with transcutaneous patches for glucose-mediated insulin delivery. ACS Nano. 2017; 11:613-620. [PubMed: 28051306]

Huang X, Liu Y, Chang C, Jiao L, Hang R, Tang B. A self-regulating antimicrobial model based on the ion-exchange stimuli. J Mater Sci Mater Med. 2015; 26:1-9.

Ishihara K, Muramoto N, Fujii H, Shinohara I. pH-induced reversible permeability control of the 4carboxy acrylanilide-methyl methacrylate copolymer membrane. J Polym Sci: Polym Chem Ed. 1985a; 23:2841-2850.

Ishihara K, Muramoto N, Fujii H, Shinohara I. Preparation and permeability of urea-responsive polymer membrane consisting of immobilized urease and poly (aromatic carboxylic acid). J Polym Sci: Polym Lett Ed. 1985b; 23:531-535.

Ismail-Beigi F. Glycemic management of type 2 diabetes mellitus. New Engl J Med. 2012; 366:13191327. [PubMed: 22475595]

Kang SI, Bae YH. A sulfonamide based glucose-responsive hydrogel with covalently immobilized glucose oxidase and catalase. J Control Release. 2003; 86:115-121. [PubMed: 12490377]

Kataoka K, Hisamitsu I, Sayama N, Okano T, Sakurai Y. Novel sensing system for glucose based on the complex formation between phenylborate and fluorescent diol compounds. J Biochem. 1995; 117:1145-1147. [PubMed: 7490251]

Kim H, Kang YJ, Kang S, Kim KT. Monosaccharide-responsive release of insulin from polymersomes of polyboroxole block copolymers at neutral pH. J Am Chem Soc. 2012; 134:4030-4033. [PubMed: 22339262]

Krajewska B. Ureases I. Functional, catalytic and kinetic properties: a review. J Mol Catal B: Enzym. 2009; 59:9-21.

Le Guen S, Noble F, Fournié-Zaluski MC, Roques BP, Besson JM, Buritova J. RB101 (S), a dual inhibitor of enkephalinases does not induce antinociceptive tolerance, or cross-tolerance with morphine: a c-Fos study at the spinal level. Eur J Pharmacol. 2002; 441:141-150. [PubMed: 12063085]

Lee MR, Baek KH, Jin HJ, Jung YG, Shin I. Targeted enzyme-responsive drug carriers: studies on the delivery of a combination of drugs. Angew Chem Int Ed. 2004; 43:1675-1678.

Lee SC, Kwon IK, Park K. Hydrogels for delivery of bioactive agents: a historical perspective. Adv Drug Deliv Rev. 2013; 65:17-20. [PubMed: 22906864]

Lenardo M, Chan FKM, Hornung F, McFarland H, Siegel R, Wang J, Zheng L. MATURE T LYMPHOCYTE apoptosis-immune regulation in a dynamic and unpredictable antigenic environment 1. Annu Rev Immunol. 1999; 17:221-253. [PubMed: 10358758]

Li Y, Liu G, Wang X, Hu J, Liu S. Enzyme-responsive polymeric vesicles for bacterial-strain-selective delivery of antimicrobial agents. Angew Chem. 2016; 128:1792-1796.

Lin KY, Lo JH, Consul N, Kwong GA, Bhatia SN. Self-titrating anticoagulant nanocomplexes that restore homeostatic regulation of the coagulation cascade. ACS Nano. 2014; 8:8776-8785. [PubMed: 25119520]

Liu F, Song SC, Mix D, Baudyš M, Kim SW. Glucose-induced release of glycosylpoly (ethylene glycol) insulin bound to a soluble conjugate of Concanavalin A. Bioconj Chem. 1997; 8:664-672. 
Lorand JP, EDWARDS JO. Polyol complexes and structure of the benzenebor-onate Ion. J Org Chem. $1959 ; 24: 769-774$.

Lu Y, Aimetti AA, Langer R, Gu Z. Bioresponsive Materials. Nat Rev Mater. 2016; 1:16075.

Lu Y, Sun W, Gu Z. Stimuli-responsive nanomaterials for therapeutic protein delivery. J Controlled Release. 2014; 194:1-19.

Mackman N. Triggers, targets and treatments for thrombosis. Nat. 2008; 451:914-918.

Maitz, MF., Freudenberg, U., Tsurkan, MV., Fischer, M., Beyrich, T., Werner, C. Nat Commun. 2013. Bio-responsive polymer hydrogels homeostatically regulate blood coagulation; p. 4

Makino K, Mack EJ, Okano T, Kim SW. A microcapsule self-regulating delivery system for insulin. J Controlled Release. 1990; 12:235-239.

Martanto W, Davis SP, Holiday NR, Wang J, Gill HS, Prausnitz MR. Transdermal delivery of insulin using microneedles in vivo. Pharm Res. 2004; 21:947-952. [PubMed: 15212158]

Matsumoto A, Ishii T, Nishida J, Matsumoto H, Kataoka K, Miyahara Y. A synthetic approach toward a self-regulated insulin delivery system. Angew Chem Int Ed. 2012; 51:2124-2128.

Mi P, Ju XJ, Xie R, Wu HG, Ma J, Chu LY. A novel stimuli-responsive hydrogel for K++-induced controlled-release. Polymer. 2010; 51:1648-1653.

Mo R, Jiang T, Di J, Tai W, Gu Z. Emerging micro-and nanotechnology based synthetic approaches for insulin delivery. Chem Soc Rev. 2014; 43:3595-3629. [PubMed: 24626293]

Mueckler M. Facilitative glucose transporters. Eur J Biochem. 1994; 219:713-725. [PubMed: 8112322]

Mura S, Nicolas J, Couvreur P. Stimuli-responsive nanocarriers for drug delivery. Nat Mater. 2013; 12:991-1003. [PubMed: 24150417]

Muzykantov VR. Drug delivery by red blood cells: vascular carriers designed by mother nature. Expert Opin Drug Deliv. 2010; 7:403-427. [PubMed: 20192900]

Owens DR, Zinman B, Bolli GB. Insulins today and beyond. Lancet. 2001; 358:739-746. [PubMed: 11551598]

Park K. Controlled drug delivery systems: past forward and future back. J Control Release. 2014; 190:3-8. [PubMed: 24794901]

Parmpi P, Kofinas P. Biomimetic glucose recognition using molecularly imprinted polymer hydrogels. Biomaterials. 2004; 25:1969-1973. [PubMed: 14738861]

Podual K, Doyle F, Peppas N. Preparation and dynamic response of cationic copolymer hydrogels containing glucose oxidase. Polymer. 2000; 41:3975-3983.

Poletto F, Lima F, Lundberg D, Nylander T, Loh W. Tailoring the internal structure of liquid crystalline nanoparticles responsive to fungal lipases: a potential platform for sustained drug release. Colloids Surf B Biointerfaces. 2016; 147:210-216. [PubMed: 27518452]

Prausnitz MR. Microneedles for transdermal drug delivery. Adv Drug Del Rev. 2004; 56:581-587.

Ravaine V, Ancla C, Catargi B. Chemically controlled closed-loop insulin delivery. J Controlled Release. 2008; 132:2-11.

Roskos K, Fritzinger B, Tefft J, Nakayama G, Heller J. Biocompatibility and in vivo morphine diffusion into a placebo morphine-triggered naltrexone delivery device in rabbits. Biomaterials. 1995; 16:1235-1239. [PubMed: 8589193]

Satav SS, Bhat S, Thayumanavan S. Feedback regulated drug delivery vehicles: carbon dioxide responsive cationic hydrogels for antidote release. Biomacromolecules. 2010; 11:1735-1740. [PubMed: 20575581]

Seminoff LA, Gleeson JM, Zheng J, Olsen GB, Holmberg D, Mohammad SF, Wilson D, Kim SW. A self-regulating insulin delivery system. II In vivo characteristics of a synthetic glycosylated insulin. Int J Pharm. 1989; 54:251-257.

Sharon N, Lis H. Lectins: cell-agglutinating and sugar-specific proteins. Science. 1972; 177:949-959. [PubMed: 5055944]

Shiino D, Murata Y, Kataoka K, Koyama Y, Yokoyama M, Okano T, Sakurai Y. Preparation and characterization of a glucose-responsive insulin-releasing polymer device. Biomaterials. 1994; 15:121-128. [PubMed: 8011858] 
Singh AK, Mukhopadhyay M. Overview of fungal lipase: a review. Appl Biochem Biotechnol. 2012; 166:486-520. [PubMed: 22072143]

Stuart MAC, Huck WT, Genzer J, Müller M, Ober C, Stamm M, Sukhorukov GB, Szleifer I, Tsukruk VV, Urban M. Emerging applications of stimuli-responsive polymer materials. Nat Mater. 2010; 9:101-113. [PubMed: 20094081]

Tai W, Mo R, Di J, Subramanian V, Gu X, Buse JB, Gu Z. Bio-inspired synthetic nanovesicles for glucose-responsive release of insulin. Biomacromolecules. 2014; 15:3495-3502. [PubMed: 25268758]

Turk B. Targeting proteases: successes, failures and future prospects. Nat Rev Drug Discov. 2006; 5:785-799. [PubMed: 16955069]

Veiseh O, Tang BC, Whitehead KA, Anderson DG, Langer R. Managing diabetes with nanomedicine: challenges and opportunities. Nat Rev Drug Discov. 2015; 14:45-57. [PubMed: 25430866]

Wang C, Ye Y, Sun W, Yu J, Wang J, Lawrence DS, Buse JB, Gu Z. Red blood cells for glucoseresponsive insulin delivery. Adv Mater. 2017:29.

Xiong MH, Bao Y, Yang XZ, Wang YC, Sun B, Wang J. Lipase-sensitive polymeric triple-layered nanogel for "on-demand" drug delivery. J Am Chem Soc. 2012; 134:4355-4362. [PubMed: 22304702]

Ye Y, Yu J, Wang C, Nguyen NY, Walker GM, Buse JB, Gu Z. Microneedles integrated with pancreatic cells and synthetic glucose-signal amplifiers for smart insulin delivery. Adv Mater. 2016; 28:31153121. [PubMed: 26928976]

Yin R, Tong Z, Yang D, Nie J. Glucose-responsive insulin delivery micro-hydrogels from Methacrylated Dextran/Concanavalin A: preparation and in vitro release study. Carbohydr Polym. 2012; 89:117-123. [PubMed: 24750612]

Yin R, Wang K, Du S, Chen L, Nie J, Zhang W. Design of genipin-crosslinked microgels from Concanavalin A and glucosyloxyethyl acrylated chitosan for glucose-responsive insulin delivery. Carbohydr Polym. 2014; 103:369-376. [PubMed: 24528742]

Yu J, Qian C, Zhang Y, Cui Z, Zhu Y, Shen Q, Ligler FS, Buse JB, Gu Z. Hypoxia and H2O2 dualsensitive vesicles for enhanced glucose-responsive insulin delivery. Nano Lett. 2017a; 17:733-739. [PubMed: 28079384]

Yu J, Zhang Y, Bomba H, Gu Z. Stimuli-responsive delivery of therapeutics for diabetes treatment. Bioeng Transl Med. 2016a; 1:323-337. [PubMed: 29147685]

Yu J, Zhang Y, Hu X, Wright G, Gu Z. Hypoxia-sensitive materials for biomedical applications. Ann Biomed Eng. 2016b; 44:1931-1945. [PubMed: 26926694]

Yu J, Zhang Y, Kahkoska AR, Gu Z. Bioresponsive transcutaneous patches. Curr Opin Biotechnol. 2017b; 48:28-32. [PubMed: 28292673]

Yu J, Zhang Y, Ye Y, DiSanto R, Sun W, Ranson D, Ligler FS, Buse JB, Gu Z. Microneedle-array patches loaded with hypoxia-sensitive vesicles provide fast glucose-responsive insulin delivery. Proc Natl Acad Sci U S A. 2015; 112:8260-8265. [PubMed: 26100900]

Zhang Y, Yu J, Shen Q, Gu Z. Glucose-responsive synthetic closed-loop insulin delivery systems. Prog Chem. 2015; 27:11-26.

Zhang Y, Yu J, Wang J, Hanne NJ, Cui Z, Qian C, Wang C, Xin H, Cole JH, Gallippi CM. Thrombinresponsive transcutaneous patch for auto-anticoagulant regulation. Adv Mater. 2016; 29:1604043.

Zhao W, Zhang H, He Q, Li Y, Gu J, Li L, Li H, Shi J. A glucose-responsive controlled release of insulin system based on enzyme multilayers-coated mesoporous silica particles. Chem Commun. 2011; 47:9459-9461.

Zhao Y, Trewyn BG, Slowing II, Lin VSY. Mesoporous silica nanoparticle-based double drug delivery system for glucose-responsive controlled release of insulin and cyclic AMP. J Am Chem Soc. 2009; 131:8398-8400. [PubMed: 19476380] 


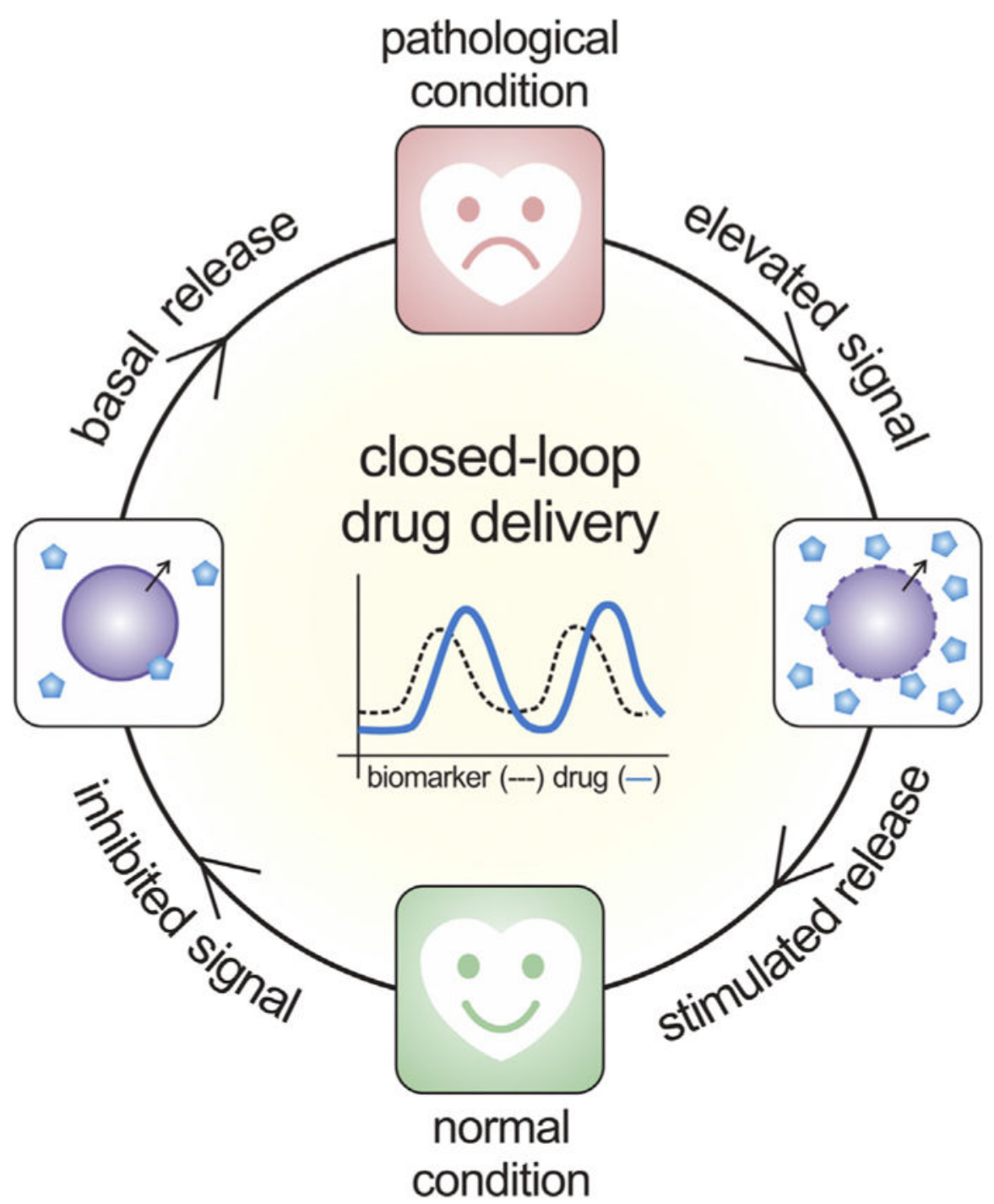

Fig. 1.

Schematic of the mechanism of closed-loop drug delivery systems that can adjust the release rate to the biosignal levels. 
A)

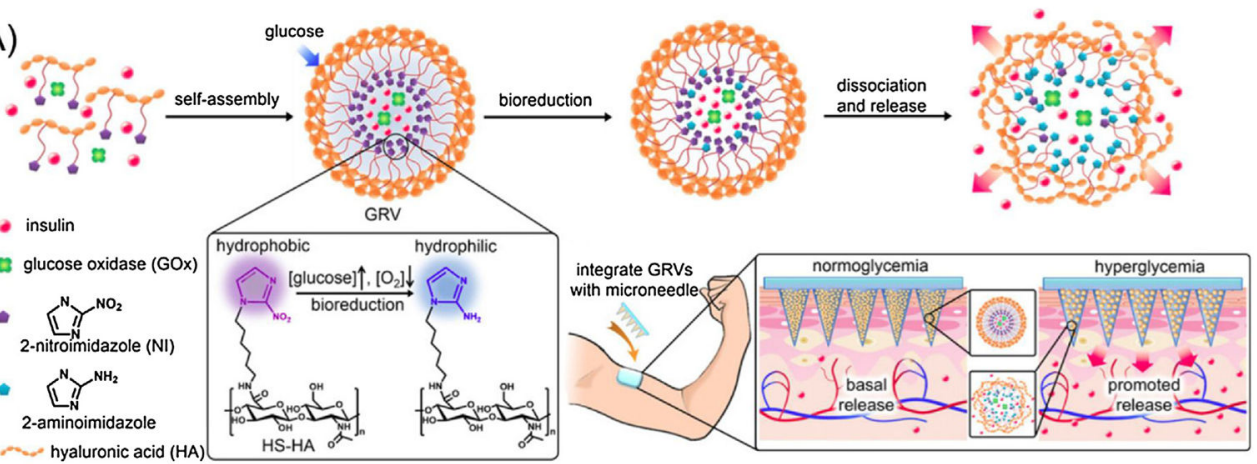

B)

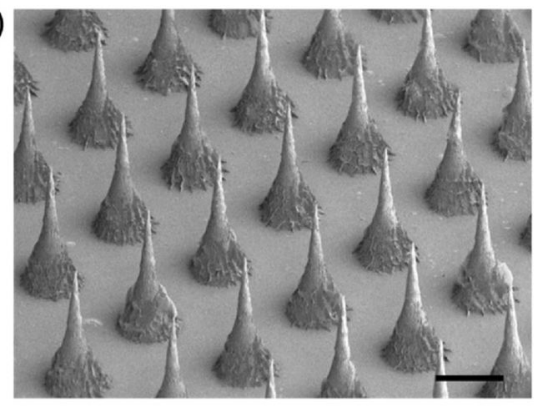

C)

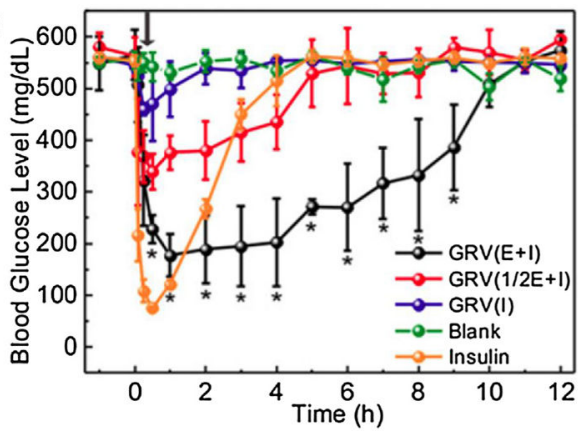

Fig. 2.

(A) Schematic of the formation and release mechanism of glucose-responsive vesicles (GRVs) and GRVs-loaded MNs for in vivo insulin delivery. (B) A scanning electron microscope (SEM) image of GRVs-loaded MNs. Scale bar: $200 \mu \mathrm{m}$. (C) Blood glucose levels of diabetic mice treated with blank MNs made from HA, MNs loaded with insulin, MNs loaded with GRVs containing insulin and enzyme (GRV(E + I)), MNs loaded with GRVs containing insulin and half dose of enzyme (GRV $(1 / 2 \mathrm{E}+\mathrm{I}))$, and MNs loaded with GRVs containing only insulin (GRV(I)).

Reproduced with permission from Ref. (Yu et al., 2015). 


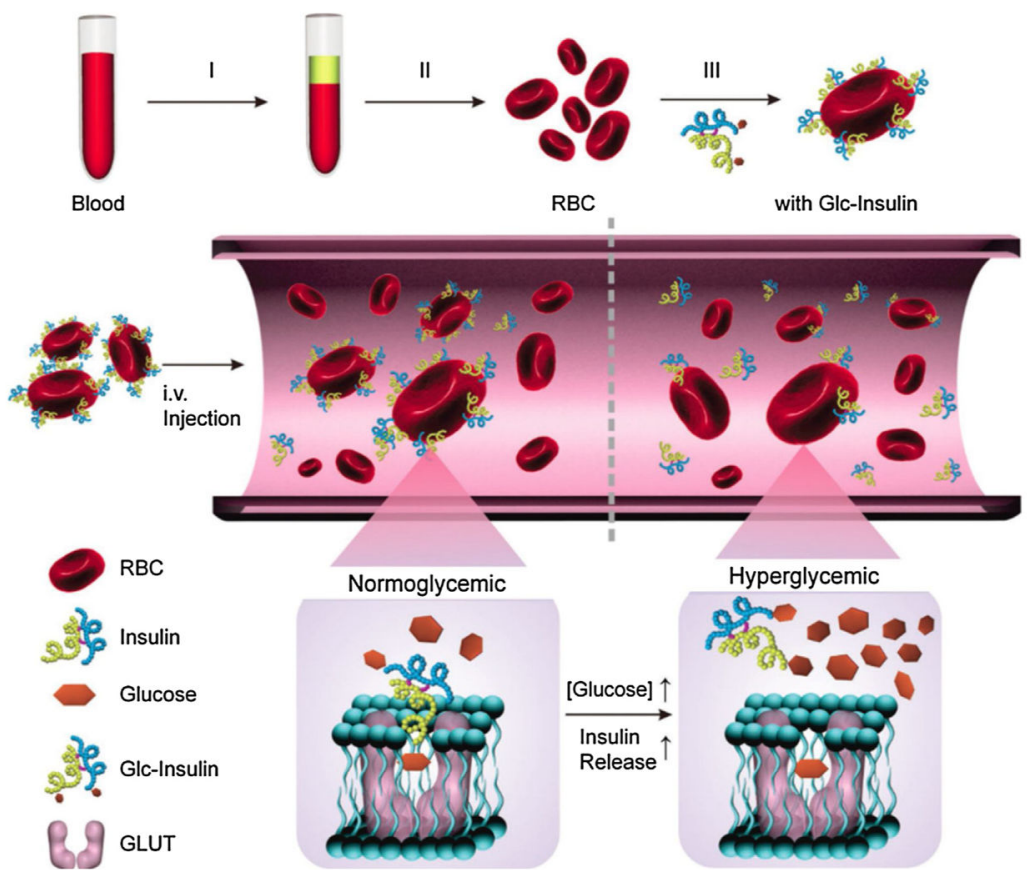

Fig. 3.

Schematic of the glucose-responsive insulin delivery system based on the GLUTs on the membrane of red blood cells. Glucosamine-modified insulin derivative was reversibly attached to red blood cells by interacting with glucose receptor/transporter on plasma membranes.

Reproduced with permission from Ref. (Wang et al., 2017). 

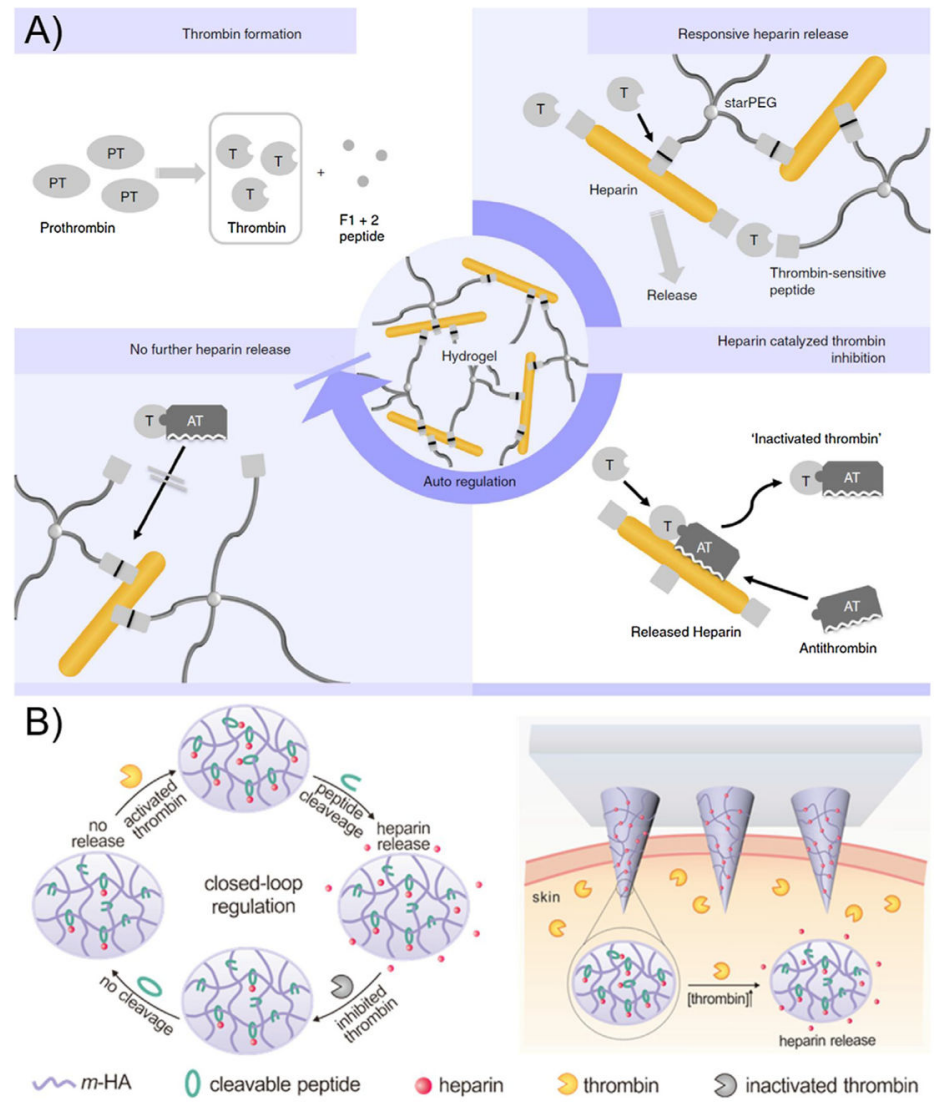

Fig. 4.

Schematic of closed-loop heparin delivery systems based on (A) a thrombin-sensitive heparin-polymeric hydrogel and (B) a thrombin-responsive microneedle patch. Reproduced with permission from Ref. (Maitz et al., 2013; Zhang et al., 2016). 


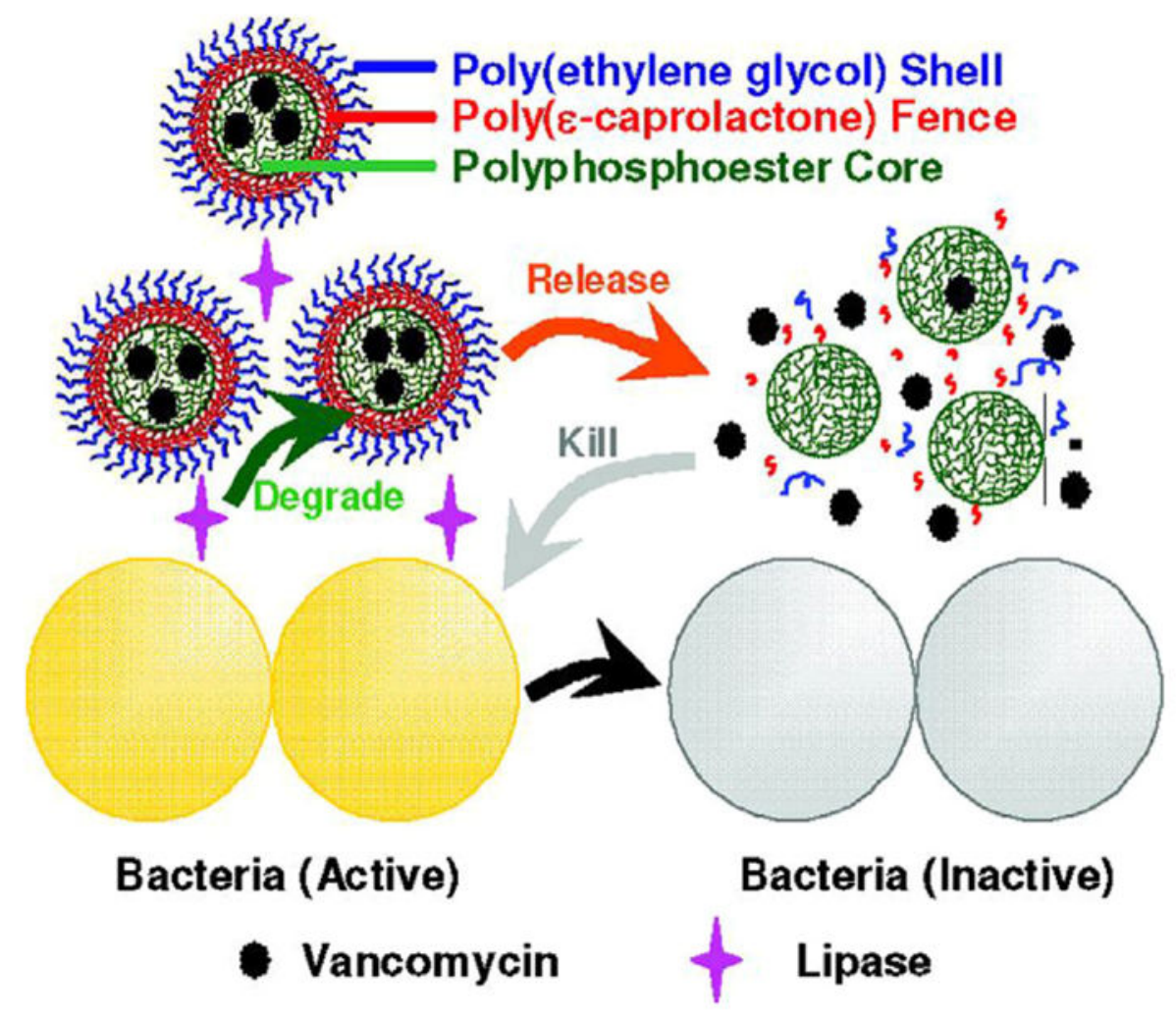

Fig. 5.

Schematic of closed-loop drug delivery systems triggered by bacterial lipase to treat bacterial infections.

Reproduced with permission from Ref. (Xiong et al., 2012). 


\section{Table 1}

Summary of representative closed-loop drug delivery systems described in this review.

\begin{tabular}{|c|c|c|c|}
\hline Biosignals & Materials & Applications & Ref. \\
\hline \multirow[t]{9}{*}{ Glucose } & pH-sensitive hydrogels & Diabetes treatment & (Hassan et al., 1997; Podual et al., 2000) \\
\hline & $\mathrm{pH}$-sensitive nano-network & & (Gu et al., 2013a) \\
\hline & pH-sensitive polymersome & & (Tai et al., 2014) \\
\hline & Hypoxia-sensitive nanovesicles & & (Ye et al., 2016; Yu et al., 2015) \\
\hline & $\mathrm{H}_{2} \mathrm{O}_{2}$-sensitive polymersome & & (Hu et al., 2017) \\
\hline & $\begin{array}{l}\text { Hypoxia and } \mathrm{H}_{2} \mathrm{O}_{2} \text { dual-sensitive } \\
\text { polymersome }\end{array}$ & & (Yu et al., 2017a) \\
\hline & Con A-conjugated polymers & & $\begin{array}{l}\text { (Brownlee and Cerami, 1979; Makino et al., 1990; } \\
\text { Seminoff et al., 1989; Yin et al., 2012, 2014) }\end{array}$ \\
\hline & Red blood cells & & - (Wang et al., 2017) \\
\hline & PBA-based polymers & & $\begin{array}{l}\text { (Kim et al., 2012; Matsumoto et al., 2012; Shiino } \\
\text { et al., 1994; Zhao et al., 2009) }\end{array}$ \\
\hline Thrombin & Thrombin-cleavable peptide & Coagulation regulation & $\begin{array}{l}\text { (Bhat et al., 2016; Lin et al., 2014; Maitz et al., } \\
\text { 2013; Zhang et al., 2016) }\end{array}$ \\
\hline \multirow[t]{2}{*}{ Lipase } & Lipase-sensitive polymers & Antimicrobial treatment & $\begin{array}{l}\text { (Li et al., 2016; Poletto et al., 2016; Xiong et al., } \\
\text { 2012) }\end{array}$ \\
\hline & Lipase-sensitive polymer & Anti-obesity therapy & (Chen et al., 2016) \\
\hline $\mathrm{CO}_{2}$ & $\mathrm{pH}$-sensitive polymers & Antidote delivery & (Satav et al., 2010) \\
\hline Urea & pH-sensitive polymers & Urea-controlled drug delivery & $\begin{array}{l}\text { (Heller and Trescgny, 1979; Ishihara et al., } \\
\text { 1985a,b) }\end{array}$ \\
\hline $\mathrm{Na}^{+}$ion & $\mathrm{Ca}^{2+}$ crosslinked alginate gel & Wound dressing & (Huang et al., 2015) \\
\hline $\mathrm{K}^{+}$ion & $\begin{array}{l}\text { Crown ether } 15 \text {-crown-5/poly }(N \text { - } \\
\text { isopropylacrylamide) hydrogel }\end{array}$ & Targeting drug delivery & (Mi et al., 2010) \\
\hline
\end{tabular}

